\title{
Conservative management of significant epidural haematomas
}

\author{
Ahmad A. Moussa ${ }^{1,2^{*}}$, Mohamed E. Mahmoud ${ }^{1}$ and Hosam A. Yousef ${ }^{3}$
}

\begin{abstract}
Background: Extradural haematomas form 0.5\% of all head injuries (Narayan and Kempisy, Principles of Neurosurgery, 2005). With the extensive blood supply to the vein, injury to the meningeal arteries leads to rapid intracranial bleeding of significant amounts of blood. These patients have traditionally been treated with urgent surgical evacuation of the haematoma to relieve the compression of the brain and brain stem (Bricolo and Pasaut, Neurosurgery 14:8-12, 1984). With the routine use of computed tomography (CT) for management of head injury patients, non-operative management is being used more often in selected patients (Narayan and Kempisy, Principles of Neurosurgery, 2005; Bricolo and Pasaut, Neurosurgery 14:8-12, 1984; Dubey et al., Neurol India 52:443-445, 2004; Offner et al., Am J Surg 192:801-805, 2006). If this can be shown as a suitable alternative to surgical intervention, it will offer a mode of treatment that has fewer potential complications and risks than the traditional surgical route.
\end{abstract}

Methods: The authors report 50 patients who had an extradural haematoma on computed tomographic scanning and did not need surgical treatment. This was during the last 3 years at Assiut University Hospital. During the same period, there were another 270 patients who had an extradural haematoma and all of them needed surgical treatment. This study is limited only to the 50 patients who did not require surgery. A CT scan was done 24-48 h after the head injury. All the 50 patients had minimal symptoms and signs which were headache and rarely vomiting but no loss of consciousness, and none of the patients had papilloedema.

Results: All the 50 patients were managed conservatively, being kept under neurosurgical care and were followed up by serial CT scanning. Their condition was either static or improving. None of the 50 patients needed surgery. They all made a complete recovery and showed resolution of the haematoma on CT scanning. This was over a period of 4-15 weeks.

Conclusion: Radiologically significant extradural haematomas can be treated conservatively. This depends on the neurological state of the patient rather than the size of the extradural haematoma. When conservative treatment is considered, adequate neurological observation is mandatory.

Keywords: Extradural haematoma, Head injury, Skull

\section{Background}

Extradural haematomas (EDH) form $0.5 \%$ of all head injuries [1].

The most common cause of an intracranial extradural haematoma is traumatic, primarily as a result of acceleration-deceleration trauma.

The pterion region, which overlies the meningeal vessels, is relatively weak and prone to fracture by trauma. Bleeding

\footnotetext{
* Correspondence: ahmad_a_moussa@yahoo.com

${ }^{1}$ Department of Neurosurgery, Assiut University Hospital, Assiut, Egypt

${ }^{2}$ Department of Neurosurgery, University Hospitals Birmingham, Birmingham, UK

Full list of author information is available at the end of the article
}

from the injured middle meningeal vessels is rapid. It grows until it reaches its peak size in 6-8 $\mathrm{h}$ from the time of injury. As the haematoma expands, it strips the dura from the inside of the skull, causing an intense headache. It compresses the brain and brain stem, causing loss of consciousness and abnormal pupil response to light which is the signal of herniation at the tentorial hiatus.

Conventionally, urgent evacuation is the accepted mode of management [2]. With the routine use of computed tomography (CT) for management of head injury patients, non-operative management is being used more often in selected patients [1-4]. 


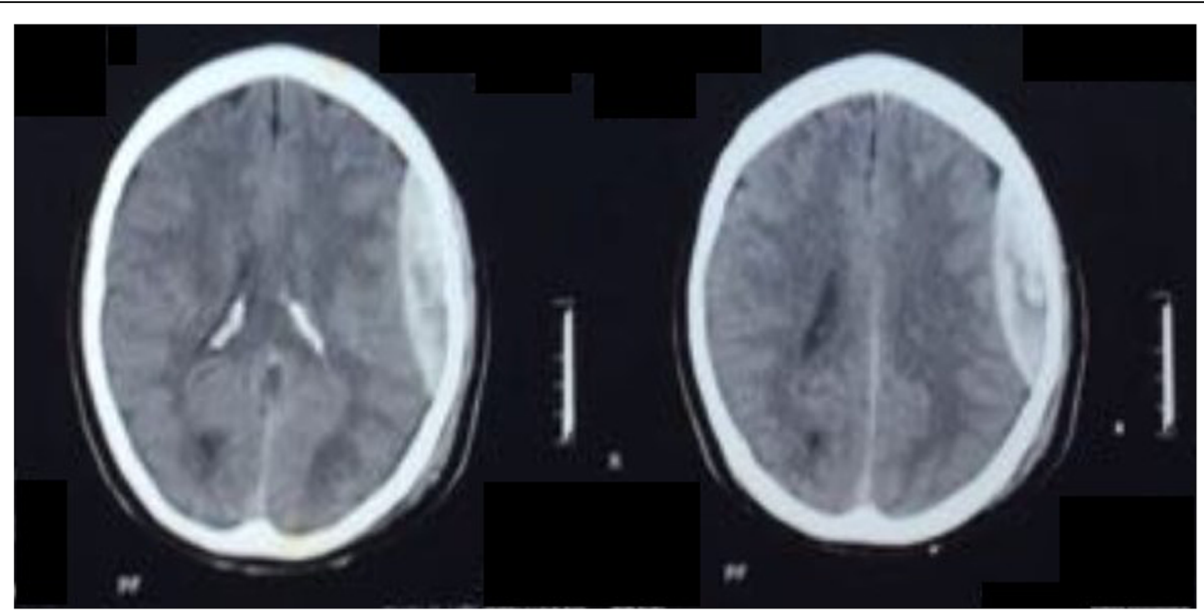

Fig. 1 An example of a CT scan of a patient after head injury showing an extradural haematoma which was managed conservatively

\section{Methods}

This is a retrograde study of 50 patients who suffered a head injury and developed an extradural haematoma on CT scanning in the last 3 years and did not need surgery.

Another 275 patients who had an extradural haematoma, during the same period and were treated surgically, were excluded from this study.

The thickness of each of the extradural haematoma on the CT scan was less than $5 \mathrm{~mm}$ with a volume of less than $30 \mathrm{ml}$. There was a midline shift of less than $5 \mathrm{~mm}$ in four patients. Out of the 50 patients, $42(84 \%)$ are male and eight (16\%) are female. Their ages ranged from $20-40$ years. There were no children among our patients.

The patients were regularly assessed clinically as an inpatient for 2 weeks and then they were followed up in the outpatient department for up to 14 weeks. They all remained fully conscious with a Glasgow Coma Scale of $15 / 15$.
None of them had papilloedema or a neurological deficit, but some of them had mild clinical symptoms such as headache, nausea or vomiting. Thirty-six (72\%) patients had a fissure fracture of the skull. None of our patients had a bleeding tendency.

The haematoma was in the temporal region in $24 \mathrm{pa}-$ tients $(48 \%)$, in the posterior fossa in four $(8 \%)$ patients and in the remainder the haematoma was either parietal or frontal.

Every patient had a follow-up CT scan twice in the first 2 weeks and once every 2 weeks subsequent to that.

\section{Results}

All our patients were successfully treated conservatively.

The extradural haematomas became less dense and smaller in size as time went on. All the haematomas disappeared by the end of 4-14 weeks, and none of our patients needed surgical treatment.

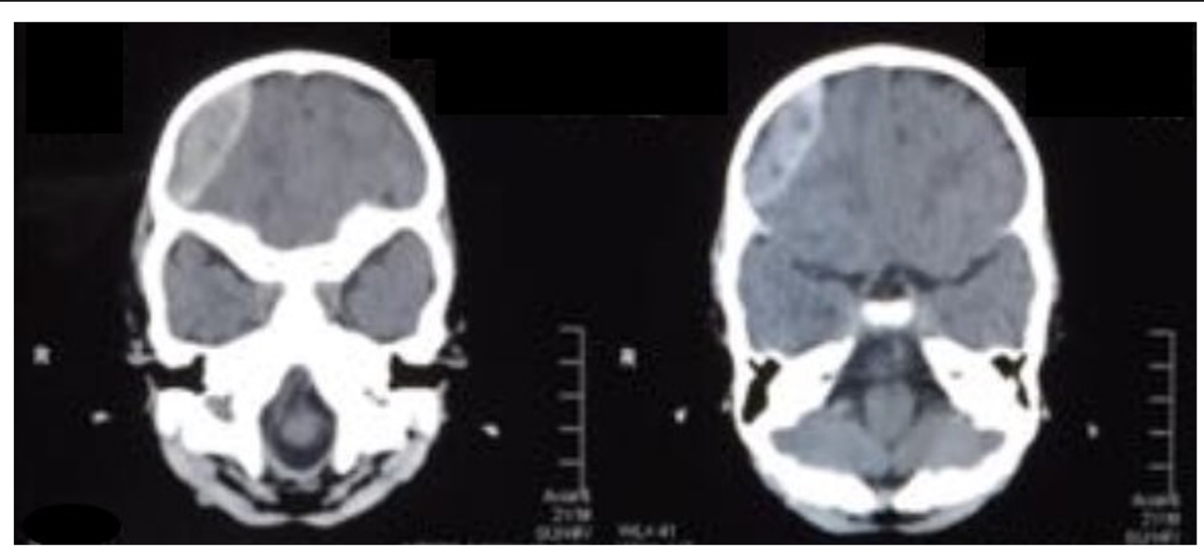

Fig. 2 A second example of a CT scan of a patient after head injury showing an extradural haematoma which was managed conservatively 


\section{Discussion}

McLaurin and Towbin mentioned in 1989 that the definitive treatment of extradural haematomas should always be surgical removal and delay of this treatment is unacceptable once the diagnosis has been established [5].

Over the last few years, there has been literature published about operative versus conservative management of extradural haematomas.

Zaitun Zakaria et al. in 2013 described three cases of extradural haematoma and their management, focusing on operative and non-operative treatment. They also reviewed, at that time, the available literature from the past three decades as well as the guidelines for management of extradural haematoma. They concluded that extradural haematoma can be managed non-operatively provided the Glasgow Coma Scale remains the same with symptomatic improvement [6].

Kulwant Singh et al. in 2010 stressed that the criteria for conservative management of extradural haematoma are: a Glasgow Coma Scale of more than 12, a small size of the extradural haematoma less than $10 \mathrm{ml}$ and a location of the haematoma other than temporal area [7].

Extradural haematoma enlargement, which needs surgery, occurs within $36 \mathrm{~h}$ with a mean time of enlargement of $8 \mathrm{~h}$ from injury [8]. All our patients were referred to us after $48 \mathrm{~h}$ from trauma (Figs. 1 and 2).

The volume of the extradural haematoma is one of the factors which influence the management strategy. In our cases, the maximum volume of the haematoma was $15 \mathrm{ml}$, but Dubey et al. [9] has recommended a volume of less than $30 \mathrm{ml}$ for conservative management while Bullock et al. [10] found the volume of $12-38 \mathrm{ml}$ suitable for conservative management.

Temporal extradural haematoma, as it is nearer to the brain stem, carries a high risk to the patients' life, but in 36 of our patients, the haematoma was in the temporal region and they were treated conservatively with satisfactory results.

Thirty-six of our patients had a fissure fracture of the skull.

R. Truncer et al. mentioned that the resorption of the extradural haematoma was partly due to the transfer of the clot into the epicranial space through the skull fracture. They concluded that in patients with a skull fractures, the resorption of the clot might be earlier than in others who do not have a skull fracture [11].

\section{Conclusion}

Radiologically significant extradural haematomas can be treated conservatively. This depends on the neurological state of the patient rather than the size of the extradural haematoma.

When conservative treatment is considered, adequate neurological observation is mandatory.

\section{Authors' contributions}

AAM is the main author and contributed to the study design and writing of the publication. MEM contributed to the data collection. HAY contributed to the revision and assessment of the patients' scans and writing of the publication. All authors approved the final manuscript.

\section{Ethics approval and consent to participate}

Research committee approval has been granted for this study by the Chairman of the Medical Ethics Committee, Prof. H. N. El Tallawy. Ethics committee approval number 17300201. Consent for participation was not needed as this is a retrospective study.

Consent for publication

Not applicable.

\section{Competing interests}

The authors declare that they have no competing interests.

\section{Publisher's Note}

Springer Nature remains neutral with regard to jurisdictional claims in published maps and institutional affiliations.

\section{Author details}

${ }^{1}$ Department of Neurosurgery, Assiut University Hospital, Assiut, Egypt.

${ }^{2}$ Department of Neurosurgery, University Hospitals Birmingham, Birmingham, UK. ${ }^{3}$ Department of Radiology, Assiut University Hospital, Assiut, Egypt.

Received: 17 January 2018 Accepted: 5 August 2018

Published online: 17 September 2018

\section{References}

1. Narayan RK, Kempisy S. Close head injury. In: Rengachary SS, Ellenbogan R, editors. Principles of neurosurgery. New Delhi: Elsevier; 2005. p. 304

2. Bricolo AP, Pasaut LM. Extradural hematoma: towards zero mortality. A prospective study. Neurosurgery. 1984;14:8-12

3. Dubey A, Pillai SV, Sastry KVR. Does volume of extradural hematoma influence management strategy outcome? Neurol India. 2004;52:443-5.

4. Offner A, Pham B, Hawkes A. Nonoperative management of acute epidural hematoma "no barrier". Am J Surg. 2006;192:801-5.

5. McLaurin R, Towbin R. Post traumatic haematomas. In: Mclaurin R, Schult L, Veres J, Epstein F, editors. Pediatric neurosurgery. 2nd ed. Philadelphia: Saunders; 1989. p. 277-89.

6. Zakaria Z, Kaliaperumal C, Kaar G, O'Sullivan M, Marks C. Extradural haematoma-to evacuate or not? Revisiting treatment guidelines. Clin Neurol Neurosurg. 2013;115(8):1201-5.

7. Bhau KS, Bhau SS, Dhar S, Kachroo SL. Traumatic extradural hematoma- role of non-surgical management and reasons for conversion. Indian J Surg. 2010:72(2):124-9.

8. Sullivan PT, Jarvik JG, Cohen WA. Follow up of conservatively managed epidural hematomas: implications for timing of repeat CT. Am J Neuroradiol. 1999;20:107-13.

9. Dubey A, Pillai SV, Sastry KVR. Does volume of extradural haematoma influence management strategy outcome? Neurol India. 2004;52:443-5.

10. Bullock R, Smith RM, van Dellen JR. Nonoperative management of extradural hematoma. Neurosurgery. 1985;16(5):602-6.

11. Tuncer R, Acikbas C, Ucar T, Kazan S, Karasoy M, Savaren M. Conservative management of extradural haematomas: effects of skull fractures on resorption rate. Acta Neurochir. 1997;139(3):203-7. 